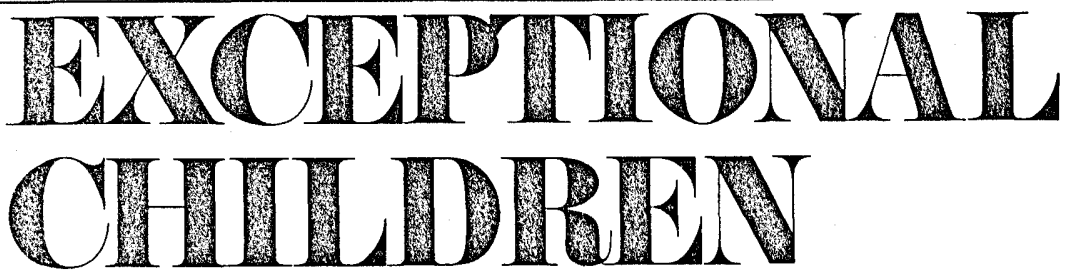

\title{
THE PRESCRIPTIVE TEACHING SYSTEM: A TEACHER EDUCATION PROGRAM
}

\section{PRESCRIPTIVE TEACHING SYSTEMS}

\section{Laurence J. Peter and Forrest G. Wisely ${ }^{1}$}

There are presently many vocal authorities who are criticizing every level and phase of education. Much of this criticism results from the belief that one of the main educational problems is the ineffectiveness of teachers. Teacher education programs are frequently credited with this ineffectiveness, and most critics are in general agreement about the need for change in teacher education.

There are a number of major discrepancies that have caused teacher education programs to fail. The failure is finally being accepted and discussed within educational ranks, and solutions are being sought. Traditionally teacher education has lacked any form of specific descriptions of the competencies required of an effective teacher. Too often, teaching has been considered such a complex process that it is impossible to analyze, and therefore cannot be taught. Those who think in this way hold teaching a mystique and believe teachers are born, not made. As a result of this thinking and a lack of a set of objectives for developing specific behaviors in student teachers, the programs consist mainly of unrelated theory and methods courses and practice teaching.

When teachers were asked what part of their teacher training program was most valuable to them after they actually started teaching, most replied, "practice teaching." But when the practice teaching experience was analyzed to discover what made it so valuable, it was difficult to pinpoint any specific reasons. Normally, the student teacher enters the classroom late in the semester after the regular classroom teacher has already set the direction for the semester's work. The student teacher has little idea of what he is to do or what he is supposed to obtain from the experience. The sponsoring teacher has only his years of experience to help guide the student teacher and may not have any basic idea of what teaching should be. The supervisor of student teachers, who may visit the student teacher once or twice during the practice teaching period, gets only a fragmented view of what the student teacher is doing, and usually the feedback he gives is ineffective in relation to teacher effectiveness.

In some cases practice teaching may be the most ineffectual part of the student

1. Laurence J. Peter is Visiting Professor, John Tracy Clinic, Los Angeles, Calif. Mr. Wisely is research assistant and a doctoral student at the University of Southern California.

() Love Publishing Company, 1971 
teacher's training. The sponsoring teacher, into whose classroom the student teacher goes, has a great influence on the teaching style the student teacher will finally exhibit. Because there are no set competencies established, the student teacher, the classroom teacher, and the supervisor have only vague concepts of the goals of the practice teaching experience. The student teacher may develop bad habits and superstitious behaviors due to the lack of stated objectives and the inconsistent and inadequate feedback about his performance from his supervisor or sponsoring teacher.

The student teacher is seldom, if ever, given the opportunity to solve any real educational problems. It has been shown through an analysis of behavior that the ability to solve problems is developed by solving problems. If the student teacher is to learn to solve educational problems, he must be given the opportunity to solve real or simulated educational problems. Regardless of how many lectures he hears or how much he reads about the problems of education, he will not learn to solve educational problems without actual experience in doing so. Therefore, the student teacher must be allowed to teach students who have learning problems instead of a group of normal children who must only be held responsible for learning.

Theory and methods courses must provide the student teacher with the knowledge and skills of attacking educational problems successfully and not proliferating the same inadequate solutions offered by the past. Many

FOCUS ON EXCEPTIONAL CHILDREN is published monthly except June, July, and August as a service to those concerned with mentally retarded and emotionally disturbed children. Subscriptions rates, $\$ 9.50$ per year. Copyright 1971 Love Publishing Company. All rights reserved. Reproduction in whole or part without written permission is prohibited. Printed in the United States of America. Second class postage is paid at Denver, Colorado.

$$
\begin{gathered}
\text { Executive and Editorial Offices } \\
6635 \text { East Villanova Place } \\
\text { Denver, Colorado } 80222 \\
\text { Telephone (303) 757-2579 }
\end{gathered}
$$

EDITORIAL BOARD

Edward L. Meyen
University of Missouri
Richard J. Whelan
University of Kansas Medical Center
Georgia State University
$\begin{array}{cc}\text { Frances Missing } & \text { Stanley F. Love } \\ \text { Senior Editor } & \text { Publisher }\end{array}$

children with learning problems are presently turned over to special services or placed in special classes. Instead of giving teachers the skills or methods for effectively dealing with various learning or behavioral problems within his own classroom, the child is frequently turned over to one or more diagnostic services. Diagnosis usually results in the child being labelled, or some reason is given for the child's problem-low intelligence, cultural deprivation, minimal cerebral dysfunction, emotional disturbance, lack of motivation. The child can be given the services of a special teacher, school psychologist, or a special class. These services provide little help to the regular teacher in learning to teach the child. Frequently it gives the teacher an excuse for not teaching the child. A real solution would be to give the teacher greater precision in the control of the process of instruction to assure the child's success.

Other alternatives given teachers for solving educational problems have been equally ineffective. One of these is to increase their education. Teachers who are having problems teaching inner city children are advised to take additional courses in sociology, cultural anthropology, ethnology, and in some cases African history to help them better understand the differences between the social values of the middle class establishment and those of the inner city, poverty subculture. Other teachers having problems with emotionally disturbed or behaviorally disordered children are advised to take courses in mental health, abnormal psychology, counseling, and therapy. No evidence exists to prove that the experts in any of these fields are any more successful in teaching these children than is the regular teacher.

The major result of these attempted solutions for solving the learning or behavioral problems of children is the mass escalation of teacher education courses, the escalation of special teachers, the escalation of non-teaching consultants, and the escalation of special classes. This escalation is The Peter Principle (Peter, Hull, 1969) in action. The Peter Principle explains why escalation frequently fails to provide a solution. The recommended remedy is the application of Peter's Prescriptions (Peter, Hull, 1969) to educational problems. This produced a solution-The Prescriptive Teaching System.

\section{PRESCRIPTIVE TEACHING SYSTEM}

The word "prescribe" means literally to "set down the direction." When sound learning principles influence the 
direction that a teacher takes it is Prescriptive Teaching (Peter, 1965). Many of the attempts to implement sound learning principles have resulted in the chaotic and unsystematic development of the progression. It is not that educational progress is absent, for significant advances have been made. It is just that compared with today's needs they fall far short.

In the last twenty years, the field of industrial engineering has accelerated the development of a methodology called the systems approach. This methodology has been an essential ingredient in much of the industrial progress of the modern world. The most dramatic demonstration of the systems approach has been in the space program with man's successful landings on the moon. It is beginning to be recognized that the systems approach is also a suitable methodology for dealing with certain human and social problems (Ramo, 1969). It can provide the unifying or integrating mechanism for utilization of our scientific knowledge about teaching and learning.

There are many definitions of systems. One of the simplest is "a system may be defined as an array of components designed to achieve an objective according to a plan" (Johnson, Rosenzweig, 1962). Another definition (Ellis and Ludwig, 1962) is "a system is something which accomplishes an operational process; that is, something which is operated on in some way to produce something. That which is produced is called output, and the operating entity is called a system." Still another definition (Kaufman, 1969) is that a system is "the sum total of separate parts working independently and in interaction to achieve a previously specified outcome." The parts or components are objects, people, machines, materials, processes, and/or behaviors all working separately and together toward a common goal. The interactions among the components are subsystems supporting the total system. The final effect of the system with all the components and subsystems working is much greater than the sum of the parts. This final effect or outcome is the observable and measurable accomplishments of the system and are best termed "objectives."

The Prescriptive Teaching System utilized the methodology of systems analysis to bring together the components of effective teaching into a total integrated input to optimize the effectiveness of the teacher.

Most systems have described man-machine relationships which can usually be quantified so that the system can be described with the specificity required for the persons to successfully operate the system. This is possible because the machine is a closed system or has quantifiable possibilities. Man is an open system because he is capable of a wide variety of behaviors. In this situation the system specifies the limited human behaviors required for operating the closed system.

The Prescriptive Teaching System is markedly different in that it deals with human interactions. In other words, the teacher and the child are each open systems, each capable of a potentially wide range of behaviors. The Prescriptive Teaching System dealt with this problem through two processes: (1) experimentation with communication of the system to teachers, and (2) reinforcement of effective teacher-child interactions.

\section{COMMUNICATION OF THE SYSTEM}

As each component in the total process was identified it was included in the system and was added to the flow chart. The system that deveolped was effective and teachers following the system were successful in achieving the stated objectives for the child.

\section{REINFORCEMENT OF EFFECTIVE TEACHER- CHILD INTERACTION}

The design of the model, the feedback provided by the Individual Instruction Record, and the system of supervision which provides immediate reinforcement for the student teacher all support sensitivity to effective teacherchild interaction. This accommodates the two open systems, the teacher and the child, because it focuses on the effective interaction between the two rather than on a specific set of behaviors. If the objective is being achieved the behaviors are reinforced. In this way the system supports effective behavior without specifying behavior as a closed system.

The Prescriptive Teaching System operates on two levels. First it optimizes the instruction of the child, and second it provides a systematic program of teacher education. It is an organization of teaching components to achieve these two objectives. The organization of the components is designed so that the system can be utilized in teaching pupils of widely varying ability and for teaching infants, children, or adults. The components of the system are instructional materials, records, procedures, human behaviors, and research instruments. A brief definition is: the Prescriptive Teaching System is an organization of definable and observable components of the process of instruction to achieve a predetermined or 
prescribed objective.

\section{PHASES OF THE SYSTEM}

The Prescriptive Teaching System provides a sequence of experiences that have been demonstrated to contribute to teacher effectiveness. The system deals with the process of instruction and provides the means by which a teacher can impart academic and social knowledge and skills to a wide range of childern-normal, handicapped, and gifted-thereby achieving the aims embodied in the philosophy of education.

The system is divided into six phases, each of which can be accomplished in one academic semester or quarter. Three phases are devoted to the systematic development of teaching competence. Phase 1, Individual Instruction, develops the skills of a tutor. Phase 2, Classrom Instruction, develops the skills of a classroom teacher. Phase 3, Therapeutic Instruction, develops the abilities required for teaching handicapped children and the counseling skills necessary for working with parents and children. Three advanced phases are devoted to teacher education. They are Phase A, Teacher Education in Individual Instruction; Phase B, Teacher Education in Classroom Instruction; and Phase C, Teacher Education in Therapeutic Instruction. (See illustration: The Phases of the Prescriptive Teaching Program.)

The purpose of the system is to develop the competencies of both teachers and teacher educators. Phases 1,2 , and 3 produce the skills required in teaching children with a wide range of ability or learning readiness. Phases A, B, and C produce the teacher education skills required in training teachers in Phases 1, 2, and 3.

\section{PHASE 1: INDIVIDUAL INSTRUCTION}

In accomplishing this phase the student teacher engages in a sequence of experiences which provide skill development in the observation, diagnosis, instruction, and evaluation of the individual child. The student teacher also learns the conceptual model of the process of instruction so that the skills can be generalized and transferred to instruction of other children.

\section{FUNDAMENTALS FIRST}

The Prescriptive Teaching System begins with individual instruction because it is a component of class- room instruction and because it can be learned separately. The skills acquired in the individual instruction phase are readily integrated into classroom instruction, and the structure of the process of instruction is also transferred to the classroom.

In learning to be an effective and creative scientist, artist, or other professional, best results are obtained when the fundamental structure and skills are mastered early. Before an artist can express himself fully, he must master the techniques of his art.

The artist who masters the fundamental techniques and conventional aspects of his craft is better equipped to become more abstract and creative in his work. The student of architecture who systematically learns the technical and conventional components of this complex profession is equipped with fundamentals required in the creative and problem-solving aspects of architecture. Similarly in the study of medicine and dentistry, skills are systematically acquired before the physician or dentist is expected to deal with complex problems requiring advanced problem-solving techniques. One can imagine the chaotic situation which would arise in these professions if the initial assignments consisted of treating patients with very complex problems.

Traditionally, for the practicum in teacher education, students are assigned a random group of children. Systems analysis shows that this is the most complex teaching task. Prescriptive Teaching begins with teaching one child so that the student teacher systematically acquires the total repertoire of identifying skills. The student teacher is thereby equipped to use the total process or any required part of it in teaching any given child. A parallel may be drawn between this and the training of a physician. In dealing with the majority of his patients the medical practitioner utilizes only a fraction of his total repertoire of medical knowledge and skill. He would be grossly inefficient as a general practitioner if he was limited in his training to dealing only with the average patient and if he was expected later in his practice to learn how to deal with severely ill or atypical patients.

In teacher training it has been assumed that by preparing the teacher to deal with a normal or average child, he will somehow through experience learn to become effective with the atypical child. The Prescriptive Teaching System has proven effective by having the teacher systematically acquire control of the complete process in the initial phase, Individual Instruction. It is essential that this phase be mastered before successive phases are 
attempted.

This phase provides the foundations of the program including both the structure and process of instruction.

\section{COMPONENTS OF PHASE 1}

Individual Instruction, as does each phase of the system, consists of two major components, classwork and practicum. The classwork component consists of regular meetings of the class of student teachers. During these meetings a variety of activities take place including discussion, observation of films or videotapes, and testing. The objective of these meetings is that the student teacher systematically acquires the structure of the process of instruction and the knowledge required to successfully teach the child. To assure that each objective is achieved a system of accountability is provided which eliminates cumulative error. A textbook, Individual Instruction, provides the conceptual model and a description of the process of instruction including the procedures for referral, observation, diagnosis, writing terminal objectives, identifying enroute objectives, selecting elicitors and reinforcers, and evaluation. Each step in the procedure is performed in simulation before it is attempted with the child. An Individual Instruction Workbook is provided for this purpose. The workbook provides programmed simulation activities utilizing the same procedures and forms as are employed in the actual teaching expeirence. This produces maximum generalization and transfer from the simulation to the real situation.

The practicum consists of tutoring a child who has learning problems. A system of recording is provided which helps the student teacher identify the effective interventions employed in the process. This system of

\section{THE PHASES OF THE PRESCRIPTIVE TEACHING PROGRAM}

PHASE 1 PROYIDES FOR THE SYSTEMATIC ACOUISITION OF THE SKILLS OF A TUTOR, PHASE II-THE SKILLS OF A CLASSROOM TEACHER, \& PHASE IIITHE SKILLS OF A MASTER TEACHER.
PHASES A, B, C PROVIDE FOR THE SYSTEMATIC ACQUISITION OF TEACHER EDUCATION SKILLS. EACH PHASE REQUIRES ONE SEMESTER. SEQUENCE MAY BE $1,2,3, A, B, C$, OR $1, A, 2, B, 3, C$, OR A COMBINATION.

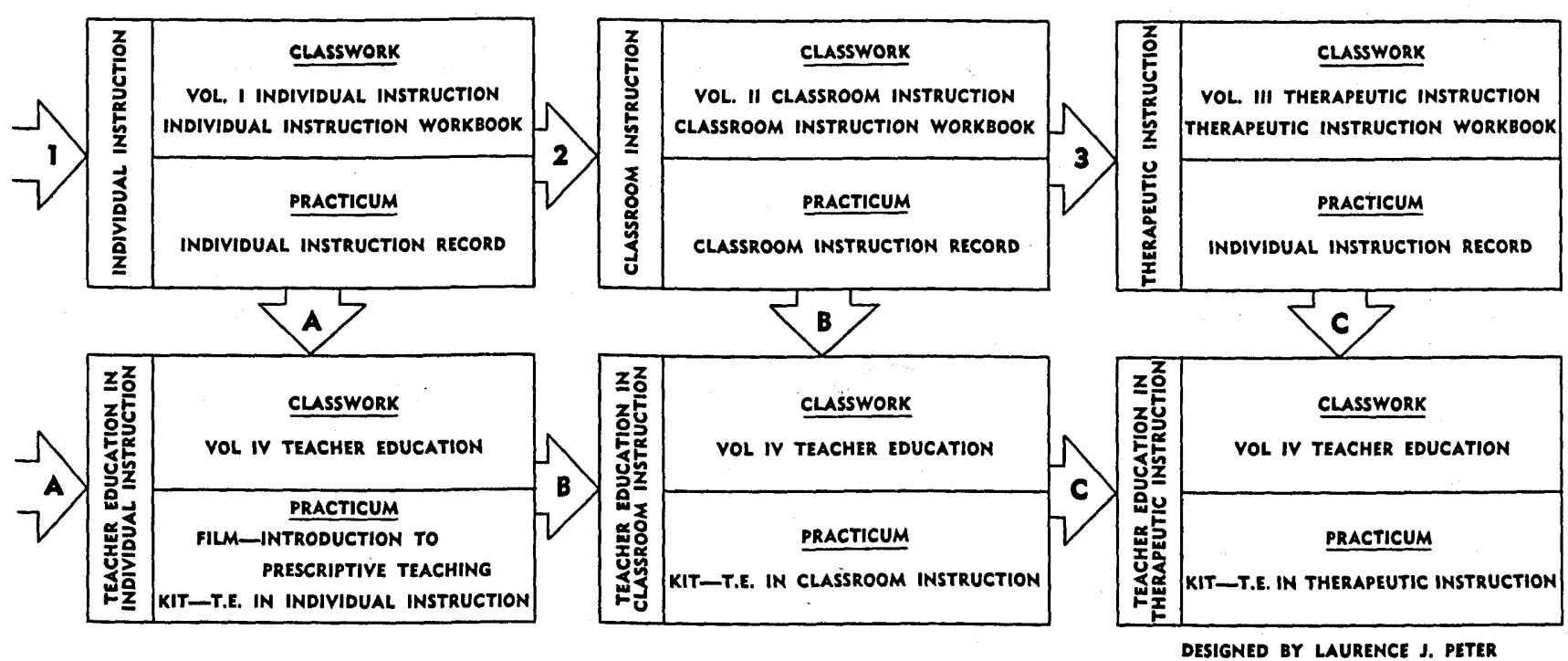


recording, Individual Instruction Record, is highly efficient and requires a minimum of teacher time. It provides (1) a record for the student teacher, (2) a report to the supervisor, (3) communication to the parent, and (4) coding for automated data processing for research.

The integrated components provide for the systematic development of complex teaching skills. The text describes a component procedure of the teaching process. The workbook provides programmed practice of the procedure through simulation. The record guides the student teacher's practicum experience in implementation of the procedure and systematic feedback to reinforce effectiveness. The combined result is effective precision teaching.

The components of Phase 1 can be utilized for independent study or as a part of the total system. Within the total system, Phase 1 is implemented through the utilization of Phase A, Teacher Education in Individual Instruction.

\section{PHASE 2: CLASSROOM INSTRUCTION}

The classwork part of this phase in conducted in a similar manner to the classwork component of Phase 1 . A textbook, Classroom Instruction, describes classroom management and illustrates the utilization of the conceptual model of the process of instruction in group or class teaching. Each procedure described in the textbook is followed by simulation exercises contained in the Classroom Instruction Workbook. Through these experiences the student teacher is prepared for the integrated concomitant practicum.

The practicum experiences are recorded in the Classroom Instruction Record. As a result of the developmentally ordered, integrated simulation and practicum the student teacher becomes skilled in classroom management, group instruction, and behavior remediation.

\section{PHASE 3: THERAPEUTIC INSTRUCTION}

The classwork portion of this phase utilizes more sharing of experience by student teachers. Therapeutic Instruction utilizes the system in teaching children who are experiencing severe learning problems and for counseling children and parents. Although the structure of the process of instruction remains the same, the application to these special problems produces a variety of procedural differences. Through group discussion and the sharing of experiences, the student teachers identify a wider range of specific applications of the process of instruction.

The practicum in this phase, Therapeutic Instruction, utilizes the same record, Individual Instruction Record as was used in Phase 1.

The graduate of these three phases has demonstrated competence in (1) tutoring an individual child, (2) managing classroom learning, and (3) instructing and counseling handicapped pupils and their parents.

\section{Phase A: Teacher Education in Individual Instruction}

Teachers who have shown in the execution of the component procedures of Phase 1 that they have mastered individual instruction are eligible to engage in Phase A. Phase A is intended for those who wish to become teacher educators in preservice or inservice programs. The participant in this phase is provided with appropriate materials for teaching and supervising student teachers in Individual Instruction. These materials include a textbook, Teacher Education; a film, Introduction to Prescriptive Teaching; and a kit of materials, Individual Instruction Teacher Education Kit, all of which are utilized in supervising, testing, and recording results. These materials provide a system of accountability and feedback assuring that the student teacher is precisely aware of the content and procedures he must master and is reinforced for his effectiveness in achieving each component. The graduate of this phase has demonstrated his knowledge of the process of instruction and the ability to perform each step in the process, and he has demonstrated his ability to teach student teachers these skills.

\section{Phase B: Teacher Education in Classroom Instruction}

Teachers who have successfully completed Phase 2 are eligible for participation in this teacher education phase. The participant in this phase is equipped with a textbook, Teacher Education, and record forms, tests, instructions, and diplomas in the Classroom Instruction Teacher Education Kit. These materials guide the process and record each student teacher's progress. This phase of the system results in accountability for each step in the classwork and practicum components of Classroom Instruction. Cumulative error is avoided through the provision of opportunities for repetition of unsatisfactorily performed procedures. The graduate of this phase of the system has demonstrated his ability to manage a classroom so that each child regularly experiences success. $\mathrm{He}$ 
has also taught student teachers these same skills.

\section{Phase C: Teacher Education in Therapeutic Instruction}

Teachers who have successfully completed Phase 3 are eligible for participation in this teacher education phase. As in the other phases they are equipped with appropriate books and materials including the textbook, Teacher Education, and a kit, Therapeutic Instruction Teacher Education Kit. The graduate of this phase has demonstrated his ability to teach and counsel children with problems and to provide guidance for parents. $\mathrm{He}$ has also demonstrated that he can teach these skills to a group of student teachers.

\section{SUMMARY}

The Prescriptive Teaching System resulted from a pioneer effort in applying systems analysis to teacher education. The system that emerged consisted of phases which could be accomplished within the usual time allotted in traditional teacher education programs. In Phase 1, the student teacher systematically acquired the component skills and conceptual model of the process of instruction for the role of the tutor in teaching a child. In Phase 2, the student teacher systematically acquired the skills of classroom management and group instruction. In Phase 3 , the student teacher systematically acquired the skills of a master teacher. Teacher education Phases A, B, and C were utilized so that the total system produced both teachers and teacher educators who were qualified on the basis of demonstrable competence. This was achieved through the accountability of the system for each component skill that the student teacher and teacher educator acquired.

The Prescriptive Teaching System, like any total system, has components which were specifically defined and organized to work toward previously specified objectives. This provided the system with built-in accountability where each component was analyzed and evaluated to determine its effectiveness in moving the system toward its specified objectives. Each component of the Prescriptive Teaching System was carefully identified, added to the system, evaluated, and simplified for maximum effectiveness within the total system. Because Prescriptive Teaching was a true system, it contained all the necessary components for effective teaching. It contained all the materials necessary to carry out an effective pro- gram of instruction for children with a wide range of problems. It provided the materials and processes for training people to use the system and for training those who had successfully learned the system to teach others to use it. The books and materials also described the steps for installing the system. The system also contained feedback control subsystems for continuous monitoring to assure that all components would continue working toward the stated objectives. Finally, all the components were tied together by communications subsystems consisting of supervision procedures and sets of forms for record-keeping and ongoing research.

\section{OUTCOMES}

There have been several research projects conducted to investigate the outcomes of the Prescriptive Teaching System. During the spring semester of 1969, the Los Angeles Unified School District and the Evelyn Frieden Center for Prescriptive Teaching at the University of Southern California co-sponsored a project for the inservice education of teachers of the educationally handicapped. The project was funded under Title VI-A of the Elementary and Secondary Act of 1965. In one phase of the project, educationally handicapped children were taught for three one-hour sessions each week at the center by teachers and graduate students enrolled in the Prescriptive Teaching program.

The Wide Range Achievement Test was administered as a pre-and post-test to pupils at the center. The interval between administrations of the three academic subtests ranged from 2.6 to 2.7 months. The average gain by the eighteen pupils who took the reading test was 7.4 months. The average gain by seventeen pupils who took the spelling test was 6.2 month.s A $t$ test was applied to the the standard scores and they were significant at the .01 level. The average gain by seventeen pupils who took the arithmetic test was 4.8 months. This gain was signifcant at the .05 level. This research was conducted by the Los Angeles Unified School District: Measurement and Evaluation Section (1969). The results are of particular interest because these children had all been classified as educationally handicapped with serious learning and behavior disorders. For these children to achieve an average of over seven months improvement in reading in less than three months is highly significant.

Two research projects have been conducted on Phases 1 and 3 of the Prescriptive Teaching System to investigate 
transfer of behaviors and academic achievement acquired during the individual instruction to the classroom. Garris (1970) investigated a Prescriptive Teaching program designed to remediate an attentional defect. He quantitatively demonstrated transfer of attentional behavior acquired in individual instruction. Using a multiple baseline technique he measured the concomitant development of attentional behavior during a child's engagement in one subject while the child was being taught to attend during engagement in another subject. He demonstrated that concomitant to individual instruction in attention during mathematics, an increase in the percentage of problems solved correctly and a decrease in interfering behavior occurred. At the same time, the percentage of errors in reading decreased during individual instruction. When the process was reversed so that attention was taught during reading sessions, reading errors decreased while attention improved during mathematics and the percentage of problems solved correctly increased. $\mathrm{He}$ also demonstrated that concomitant improvements in study-related behavior and achievement occurred in the regular classroom.

The other research project (Lieberman, 1970) showed that study-related behaviors and academic achievement acquired during individual instruction were transferred to the classroom. He also quantitatively demonstrated that the child increased his adaptive social behaviors in the home concomitantly.

Another research project, concerned with Phase 2 of the system (Hayes, 1967), investigated an application of Prescriptive Teaching using individual instruction within a special classroom based upon behavior modification. A sample of thirty children diagnosed as underachieving and emotionally disturbed were randomly assigned to three groups. The first group received Prescriptive Teaching along with behavior modification techniques for academic achievement and behavior adjustment. The second group received only the behavior modification program. The third group were in special classes operated along traditional lines. After two months of the treatment, group 1 was rated significantly higher on academic achievement than group 2 and group 3. Groups 1 and 2 scored significantly higher on behavior improvement than group 3. This study demonstrated that a classroom operated on behavior modification principles provides an effective behavior management technique but that Prescriptive Teaching identified and remediated specific educational handicaps.
There are many other aspects of the Prescriptive Teaching System that will need further research. To accommodate this research, one copy of each form in the Individual Instruction Record book has been designed for coding the information for automated data processing. This permits continuous and systematic research on many aspects of the Prescriptive Teaching System.

The McGraw-Hill Book Company is publishing the Prescriptive Teaching System, including the textbooks, workbooks, record forms, film, and kits. Phase 1, Individual Instruction, will be available early in 1972 .

\section{REFERENCES}

Andrew, Gary M., and Moir, Ronald E. Information-Decision Systems in Education. Itasca, Illinois: F. E. Peacock, 1970.

Ellis, D. O., and Ludwig, F. J. Systems Philosophy. Englewood Cliffs, New Jersey: Prentice-Hall, 1962.

Garris, R. P. "The Use of Behavior Rating as an Indicator of Concomitant Development in a Prescriptive Teaching Program." Unpublished doctoral dissertation, Los Angeles: University of Southern California, 1970.

Goodman, L. "Evaluation of Direct Observations as an Assessment Technique in a Prescriptive Teaching Program." Unpublished doctoral dissertation, Los Angeles: University of Southern California, 1970.

Hayes, M. E. "Prescriptive Teaching as a Supplement to Behavior Modification in the Remediation of Learning Disorders." Unpublished doctoral dissertation, Los Angeles: University of Southern California, 1967.

Johnson, R. A., Kast, F. E. and Rosenzweig, J. E. The Theory and Management of Systems. New York: McGraw-Hill Book Company, 1962.

Kaufman, Roger A. "The Use of System Analysis in Educational Planning." Unpublished manuscript, Los Angeles: 1969.

Lieberman, J. N. "A System of Transfer and Generalization of Educational Skills and Adaptive Social Behaviors." Unpublished doctoral dissertation, Los Angeles: University of Southern California, 1970.

Los Angeles Unified School District. Evaluation Report 1968-69, ESEA, Title VI-A. Los Angeles: Measurement and Evaluation, 1969.

Peter, Laurence J. Prescriptive Teaching. New York: McGrawHill Book Company, 1965.

Peter, Laurence J., and Hull, R. The Peter Principle: Why Things Always Go Wrong. New York: William Morrow, 1969.

Ramo, Simon. Cures for Chaos. New York: McKay Publishing, 1969. 


\section{DEVELOPING THE PROCESS OF THOUGHT WITH THE \\ LEARNING DISABLED CHILD}

\section{Edward G. Scagliotta ${ }^{1}$}

Teacher presentation of facts, followed by student assimilation and regurgitation, does not necessarily constitute a cognitive process. Rather, application of the learned information and adaptation to different sets of values and circumstances should be the primary objective. Learning to think pertains not only to the ability to absorb input, but also requires that output reflect general usage and relevancy adaptable to a wide range of incidents and situations.

\section{FORMULATION OF OBJECTIVES}

In order to initiate the process of thought, an objective or purpose needs to be formulated. Once identified, it becomes the motivating device to learning, reflecting the needs and desires of the learner. Such purpose may be child and/or teacher oriented. That is, sub-primary goals may be a desire of the teacher in the general projection of the primary intent for the child.

As an approach to achieving this intent, simultaneous sense stimulation is suggested. This refers to the utilization of as many of the senses as possible during the learning experience. As an example, for the child to conceptualize a pineapple, visual, auditory, olfactory, taste, and tactile-kinesthetic stimulation become essential modalities to the development of an appropriate mental image. What this approach insures is active and almost total sensory involvement. Mere observation or listening may do little to enhance the learning climate. The experience of manipulating the tools of learning, whatever they may be, provide a solid foundation on which to build.

\section{PRESENTATION}

In considering the organization of presentation, it is essential that the simple precede the complex in successive developmental steps and that significant parts become significant wholes. Of paramount importance is the cognition of a simple whole that can be transferred to more complex and varied entities. For example, a sphere is not merely a simple geometric form to be identified as such,

1. Edward G. Scagliotta is Director of The Midland School, North Branch, New Jersey. but may represent a variety of concepts directly related to implementation. A globe, baseball, ball bearing, and marbles are all examples of a sphere, but certainly should be more meaningful to the student than the initial conception of a simple geometric form. In short, cognitive learning is a process directed toward established and transferable thought patterns adaptable to changing circumstances and situations.

\section{Conditioning}

Conditioning is also essential for the development of the learner. The conditioning process may be generated through a reward system, a system which reinforces acceptable or desirable responses with much fanfare. Such a reward is usually a consumable (food) or a tangible (trinket) which is always accompanied by verbal praise. As the conditioning process increases in holding power, it is expected that the combined form of consumable, tangible, and verbal will be transferred to the verbal alone and become a complete and satisfying student reward. It is a cardinal principle that only positive responses be brought to the attention of the child, while negative behavior is generally ignored or at least not accentuated to the point that more attention is paid to the negative aspects rather than to the positive. Punishments and attention to failures, fears, and faults only tend to further reinforce that which is contrary.

The assumption that the learner is usually aware of the consequences of his response can be fallacious. Learned behavior may not always feed back the correctness or error of a response. In school, the child who is supplied milk from a central distribution point during lunch may assume permissiveness in taking milk at any time during the day, much as he would in the home environment. As this illustration points up, an inappropriate generalization had been projected with little or no awareness of the maladaptive behavior. The obvious may not always be so; therefore, discrimination learning becomes necessary to provide specífic experiences in differentiating between appropriate and inappropriate behavior as applied to changing circumstances.

\section{Modeling}

Another approach to establishing the correctness or inappropriateness of a response is to broaden the child's stimulation through effective modeling. A suitable model 
is one who, through actions and reactions, is able to serve as a positive example of approved behavior. In an attempt at correction, adults often tend to reprimand or criticize the child's response rather than to instruct properly. Modeling in a conscious and positive manner, through a consistent pattern of demonstration and verbalization, intensifies the acquisition of responses that were not necessarily a part of the child's previous behavior. Although effective modeling takes a good deal of practice and patience, once achieved it generally improves the child's sharpness in shaping accordant responses.

\section{GOALS OF CHILD}

To this point motivations and adaptive behavior have been of prime concern, but what of the child's goals: to what degree do past successes and failures contribute to the establishment of future objectives? Does the child have a sense of direction, a place or position at which he hopes to be in time? For learning to take place the learner must be involved in goal setting, for he, too, has a vital stake in his development and future. Involve him. Teacher-pupil planning-not only daily, but also projected-can do much to insure continuous positive response to the learning environment. Allow him to help decide what his future may be. Provide the structure, control, and regimentation he needs, but be flexible and bending in the relationship. Decision-making need not always be authoritative; it can be a cooperative venture.

With the development of the process of thought comes inevitable conflict and frustration. Periods of emotional excitability as a child strives to compensate for learning deficits are real, and require thoughtful teacher consideration and attention. As with all learning, emotional upheavals and difficulties in functioning are likely to occur. As a result, individual stresses in the learning climate, due to both child and teacher ambivalence, tend to trigger adverse behavior in an attempt to camouflage and compensate. Identification of the contributing factors for such behavior requires qualitative analysis to assure a continuity in the thought process.

The emotional confrontation in the learning environment is characterized simultaneously by expressions of child anxiety and anger with corresponding teacher apprehension and misgiving. In such an episode the child is most uncomfortable, and sometimes quite pained, to the degree he is ready to fight, to retailiate for what he truly considers a wrong. His heart beats faster, he begins to breathe heavier, he perspires, his muscles tense, and his face flushes noticeably, all to the detriment of mental functions. His intellect is no longer in command. Teacher anxiety differs slightly in that anger is usually not directed toward the child, as such, but rather is indicative of troubled and confused thoughts. Further, the apprehension looms as a fear, a panicked concern over the inability to remedy the situation at the particular moment of occurrence. Nevertheles, the teacher's nervous system reacts in much the same way as the child's-the emotions dictate the actions.

Teacher understanding of the child's emotional behavior is vital to maintaining clear, logical thought. Attention to objectives, materials, procedure, and education theory are for naught if the learning climate is threatened by discord.

Gains in the processes of thinking and learning can be assured when the teacher is prepared to accept the learning disabled child as a human being-one who manifests likes and dislikes, pleasures and aspirations, desires and appreciations, attitudes and discriminations, ambitions and emotions. What the teacher does with these characteristics in preparing the mind and attitudes is the key to the child's functional success.

\section{REFERENCES}

Bugelski, B.R. The Psychology of Learning Applied to Teaching. New York: Bobbs-Merrill, 1964.

Clarizio, H.F., and Yelon, S.L. "Learning Theory Approaches to Classroom Management: Rationale and Intervention Techniques," The Journal of Special Education, 1, 3, 1967.

Hilgard, Ernest R., and Bower, Gordon H. Theories of Learning, 3rd ed. New York: Appleton-Century-Crofts, 1966.

Kerlinger, Fred N. Foundations of Behavioral Research. New York: Holt, Rinehart and Winston, 1967.

Kessler, Jane W. Psychopathology of Childhood. Englewood Cliffs, N.J.: Prentice-Hall, 1966.

Rambusch, Nancy McCormick. Learning How to Learn. Baltimore, Md.: Garamond Press, 1963.

Ross, Alan O. "The Application of Behavior Principles in Therapeutic Education," The Journal of Special Education, 1, 3, 1967.

Ullmann, L.P., and Krasner, L., eds. Case Studies in Behavior Modification. New York: Holt, Rinehart and Winston, 1965. 
MISSOURI CONFERENCE ON THE CATEGORICAL/ NON-CATEGORICAL ISSUE IN SPECIAL EDUCATION

On March 22 and 23, 1971, 260 special educators representing thirty-three states convened on the campus of the University of Missouri-Columbia. The general purpose of the conference was to explore the implications of the categorical/non-categorical issue for teacher education. The intent of the conference was to examine the purposes served by the use of traditional categories and organizational systems and to explore the bases of indicators for other approaches to serving exceptioanl children. The conference structure was designed to maximize relevant input and to allow for analysis of views expressed. To accomplish this objective four features were built into the conference.

1. Several individuals from special education and related fields were invited to present formal papers.

2. A "call for papers" resulted in two general sessions for submitted papers. One session was devoted to a presentation by the Special Education faculty of George Peabody College for Teachers on their experimentation with a non-categorical training model. The second session included papers presented by Maynard Reynolds, the University of Minnesota; Enid Wolf, Washington D.C., Public Schools; Steve Lilly, the University of Oregon; Howard Spiker, Indiana University; and Paul Retish, the University of Iowa.

3. In addition to the invited presenters, nine other individuals were selected to serve on a panel assigned the task of formulating a statement on the implications of the categorical/non-categorical issue for teacher education. The panel was chaired by Maynard Reynolds and included Samuel Ashcroft, George Peabody College for teachers; Bruce Balow, Bureau of Education for the Handicapped, U.S.O.E.; Samuel Guskin, Indiana University; Clifford Howe, University of Iowa; Donald McMillan, University of CaliforniaRiverside; William Reid, University of Florida; Louis Schwartz, Florida State University; and Glenn Vergason from Georgia State University.

The panel members participated in the general sessions and also met in closed sessions following each general session.

4. Small group discussion sessions involving the audience were held following each general session.

In contrast to the emotional response which has characterized many previous discussions on this issue, the tone of this conference was objective. The major theme which emerged was an emphasis on alternative strategies, primarily non-categorical in nature, for the provisions of educational services to children and for the preparation of personnel. The attitude of the presenters was one of calling attention to areas in which our profession appears to be vulnerable. At the same time, they addressed themselves to the options which are available to professionals in the field while not belaboring the possible mistakes or "sins" of the past. Rather, past practices were explored in terms of their contribution to the current status of education for handicapped children and possible inhibiting effects they may have on children in the future.

The implications of the issue relative to minority groups, legislative bodies, administrative structures, humane public policies, philosophical considerations, teaching styles, and the varied learning pattem of children also received considerable study.

It is not feasible in this discussion to report in detail the proceedings of the conference. However, as an introduction to the full proceedings which will be released later, excerpts from the conference are presented. In some cases the statements have been paraphrased, and in others they are direct quotes from the speaker. They have obviously been taken out of context, but in general they are considered representative of the tenor of the presentation.

\section{"Parameters of the Issue" \\ James J. Gallagher \\ Frank Porter Graham Child Development Center}

1. The major changes now occurring in special education today (itinerant teacher, resource rooms) are too superficial. We need to redesign special education and our attitude toward the whole delivery system of services. The cry for change comes from all categorical areas.

2. We don't need to destroy our organizations, only humanize them. It is a devastating critique of our educational organizations that many teachers feel that no one cares. The organization seems to exist to prevent effective action rather than to stimulate it. 
3. Some of the major headaches in special education relate to the absence of an effective backup or support system or organization for the special education teacher or clinician. In most cases, it is all too clear that the educational support systems necessary to get complex tasks done are not there. We need support systems in the areas of: (1) planning and evaluation, (2) training, (3) educational communication centers, and (4) demonstration centers of excellence.

\section{"The Use and Abuse of Educational Categories" Christopher Lucas, University of Missouri Associate Professor of Philosophy}

1. Questions regarding the viability of labels and categories in special education involve logical, conceptual, and philosophical as well as empirical issues.

2. Contrary to some allegations, it is plausible to argue on historical grounds for the original good intentions behind separate classes; likewise, from a philosophical perspective, the necessity of labels, it is argued, inheres in the efficacy with which they mark out educational phenomena for attention.

3. A more careful separation of the logical, normative, and empirical components of the categorical/non-categorical controversy would not only serve to reveal the fundamental issues involved, it might also point to their resolutions.

\section{"Misuse of Categories and Classification in Special Education" Frank Wilderson, Associate Dean \\ College of Education, University of Minnesota}

1. Categories as we have structured them in special education contain few contributions from the child, his parents, or his advocates in terms of his perceptions, but rely most heavily upon so-called objective examination findings in terms of status and conditioning.

2. Special educators have a new duty to perform if they are to avoid the charge of continued "misuse of categories and classifications schemes in special education." Their new duty is that of developing a relevant body of knowledge for their practice including a positive pedagogy for minority group children.
3. There must be a concerted effort to challenge and test the current conceptions with which most conceptions of child development, childhood exceptionality, and school learning processes rest, and to determine their applications to the education of Americans from diverse backgrounds. This would be in contrast to basing educational programs for such children on judgments extrapolated from research on white children.

4. If teachers are to see the educational leadership role as one of guidance rather than categorizing and labeling, then they must be exposed to a training program in which they guided rather than labeled.

5. Conferences such as this one can get rid of trivia, but they cannot get at causes. To eliminate causes requires not occasional conferences but campaigns, and indeed ourselves!

\section{"Some Questions from a School Administrator" John W. Melcher, Assistant Superintendent Wisconsin State Department of Public Instruction}

1. Although many special educators are striving for greater "normalization" of educational programs for handicapped children, they should be cognizant of the fact that a large percentage of "regular" teachers and administrators continue to advocate the special class or segregated approach to serving children with special needs.

2. If a total collaborative effort in initiating new approaches to special education programming is to bear fruit, then answers or solutions must be found relative to the following questions:

a. What readiness, both professional and emotional, does the "regular" class teacher have for the return of handicapped children to her classroom?

b. What changes need to occur in a college or university's "regular" teacher-training program in order to adequately prepare generic elementary or secondary teachers for serving handicapped children?

"Categorical or Non-Categorical-

The Perspectives of a Teacher Trainer"

Oliver L. Hurley

Yeshiva University

1. The impact of this issue if it leads to declassification 
will reverberate throughout all of the halls of ivy and not just in the special education wing.

2. We cannot decategorize unless we get involved in the whole of education, not just special education. We cannot complain about the output if we don't attempt to provide some input.

3. This redefinition of roles would create a need for intensive involvement in in-service training to teachers, both regular and special, and the development of new teacher training models for the retooling of our pre-service training.

4. Moving toward a non-categorical approach to educating mildly handicapped children means that all teachers must become proficient in such areas as educational diagnostics, remedial techniques, behavior management, and problem solving. This will necessitate a closer linkage between training institutions and the schools and the integration of extensive practicum experiences in preservice training.

"Public Policy and the Education of

Children with Special Needs"

Burton Blatt

Syracuse University

1. The term "child with special needs" should be applied to any individual under twenty-one years of age who because of adjustment difficulties arising from intellectual, emotional, physical, perceptual, linguistic, or cultural factors, or any combination thereof, requires special services or support in order to achieve his fullest possible development. Labels should not be used to identify a child by pathology or deviancy.

2. Even though special education legislation has increased markedly during the past year, dissatisfaction prevail among those concerned for the handicapped because inconsistent and discriminatory statutes still exist.

3. Along with the removal of "labels," appropriate state agencies should define the needs of children in terms which would emphasize development rather than deviancy. New regulations should "encourage and reward local school programs that seek to integrate and normalize education opportunities for all children with special needs."

4. Statutes should be revised and implemented so that mandatory services could be provided for all children with special needs with incentives for the provision of community placement (public or private) and with funding regulations which would permit the less affluent communities to provide quality education.

5. A "Child Development Model," with emphasis given to the establishment of a state agency which would be responsible for all children with special needs, regardless of their prognoses, is needed. To encourage quality services and programs, citizen advisory groups (composed primarily of parents) should be organized throughout a state so that citizen-consumers could become more active in policy and decision-making.

\section{"Implications of the Issue for Higher Education" \\ Alfred Schwartz, Dean \\ College of Education, Drake University}

1. Technology has fostered compartmentalization in higher education. This has inhibited communication between the generalists and the specialists.

2. Special education must make an impact on all of education. Without all of education supporting the noncategorical approach its chances for success are minimal.

3. Intensive specialization tends to limit our vision.

4. Labels should not be used as a substitute for meaningful programming.

In the submitted paper section, the focus was primarily on situation-based educational models and training models which call for more humane concern on the part of teachers and specific instructional competencies.

Steve Lilly called for a definition of exceptional situations rather than exceptional children; a "zero-reject" service model which would make it administratively impossible to separate a child from a regular class program for any reason; and, for trained instructional specialists as the major support system for classroom teachers.

Howard Spicker from Indiana University stressed the 
need for competency-based teacher training models organized around structured modules. He urged an assessment of existing training models with a movement toward models which are more responsive to the needs of the field.

Paul Retish from the University of Iowa discussed a project aimed at identifying and changing attitudes of school personnel towards minority group children. His data suggest that it is difficult for teachers to avoid stereotyping minority group children.

The Special Education Faculty of George Peabody College for Teachers described its new program which has been reorganized. The training program is termed InSTEP (Interrelated Special Training of Educational Personnel) and features a focus on training educators to function in varying educational delivery systems: special education services for the excluded child; early education for the exceptional child in the regular classrooms; resource education for the exceptional child in regular classrooms; and community education to provide for the exceptional child in his family, neighborhood and school. These four foci are labeled as task forces and will represent the emphasis of training for upper division or graduate level students.

The above comments represent the flavor of the conference but by no means offer complete coverage of the ideas and reactions exchanged. All presentations were video taped and all group discussions were recorded. Each participant was also asked to respond to a brief questionnaire regarding attitudes towards the issue. This information, along with the text of major papers and the position statement of the panel, will be incorporated into a publication of the proceedings. The position statement of the panel is in the process of being finalized and will be included in the proceedings. Persons interested in the proceedings should contact Edward L. Meyen, Department of Special Education, University of Missouri-Columbia, 515 South Sixth Street, Columbia, Missouri 65201.

The conference was supported by funds from the Graduate School, University of Missouri-Columbia, and the Division of Training, Bureau for the Education of the Handicapped, U.S. Office of Education.

\section{NEW BOOKS}

Positive Classroom Performance: Techniques for Changing Behavior by Patricia A. Gallagher. This new book gives practical ideas for development of positive classroom performance and decrease of negative performance. Specific classroom examples of behavior modification projects for classroom teachers are presented. It is available for $\$ 2.00$ from Love Publishing Company, Department EC-3, 6635 East Villanova Place, Denver, Colorado 80222 .

Learning Games for exceptional Children, by Avaril Wedemeyer and Joyce Cejka. This book shows how games can be used as an active part of the learning process. It is geared to elementary grades and contains arithmetic and language activities. It is $\$ 4.95$ from Love Publishing Company, Department EC-3, 6635 East Villanova Place, Denver, Colorado 80222.

\section{ALERT}

American Association on Mental Deficiency will have its annual meeting at The Shamrock Hilton Hotel in Houston June 13-19, 1971.

The European Association for Special Education will hold an International Trade Fair on Special Education and International Conference on "Teaching the Handicapped Child." The meetings will be in Norrikoping, Sweden, July 25 to August 2, 1971. Please direct inquiries to R. Hermelin, 85/86 Newman Street, London, W.1.

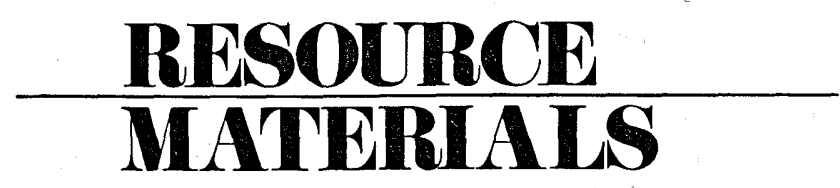

By Avaril Wedemeyer and Joyce Cejka

\section{TEACHING RESOURCES CORPORATION}

The Vanguard school program is a complete supplementary program for the training of perceptual-motor skills. Although the materials were designed for general 
use in kindergarten and primary grades, they also include developmental and remedial activities for slow learners, the perceptually handicapped, and older students. It has been used successfully in the Vanguard Schools with students from age 5 to 14 .

There are four parts to the program: body awareness, discrimination and classification, and concepts of spatial relationships. Actvities for individual skill practice lead into paired activities and classroom group games. Workbook exercises are combined with motor activities as the sequences progress with the exception of the body awareness section.

A teachers specimen set which consists of one set of Guides and workbooks with acetates for all four parts of the program is priced at $\$ 9.95$. This is a complete set of materials for the instructor and one student. Each part may also be purchased separately along with additional student workbooks. More complete information on the contents of each part of the program is available from Teaching Resources Corp, 100 Boylston St., Boston, Mass. 02116.

\section{INSTRUCTIONAL MEDIA}

The percepual communication skills series presents auditory training material at 3 levels: primary, intermediate, and secondary. The Auditory Awareness Teachers Handbook is priced at $\$ 7.50$ and covers material for all three levels. The student material is in workbook format priced at $\$ 1.25$ each. Training is provided at each level in developing listening skills, awareness to environmental sounds, recognition of structure and arrangement, drawing conclusions, vocabulary development, and improving memory.

A multi-level program in workbook format provides problems and exercises for training and developing visual skills such as visual acuity, visualization, patterns of closure, structural patterning, memory training, and speed of word and object recognition. The activities are teacher directed at the elementary level and self-directed for junior and senior high use. "Developing Visual Awareness and Insight" is available at $\$ 1.25$.
These materials may be obtained from Instructional Media, 1415 Westwood Blvd., Los Angeles, California 90024 .

\section{WASHINGTON REPORT \\ COLLEGE AID FOR HANDICAPPED}

Grants totaling $\$ 10$ million have been awarded to 146 colleges and universities under a program for disadvantaged and physically handicapped college students.

The program, called Special Services for Disadvantaged Students in Institutions of Higher Education, was authorized under an amendment to the Higher Education Act of 1965 and is administered by the Division of Student Special Services within the U.S. Office of Education.

Special Services has as its goal helping the handicapped student graduate from college and pursue graduate or professional education. By providing aid specific to the needs of each student the program could help many succeed who otherwise might be forced to leave college because of disabilities.

In order to achieve this goal Special Services will provide comprehensive programs which will include counseling, tutoring, modified curriculums, and summer sessions. Students who need additional personal assistance in order to complete their assignments may receive such help as is necessary. For example, a typist may be provided for an amputee or a reader for a blind person. The programs will consider the student's total environment for learning and developing on and off the campus, thus coordinating the academic life with community institutions where possible.

FOCUS ON EXCEPTIONAL CHILDREN back issues are available. Single copies $80 \phi, 2-9$ copies $70 \phi$, and 10 or more copies $50 \phi$ each. 


\section{CLASSTROOM FORUM}

Edited by Austin J. Connolly, University of Missouri

\section{PROBLEM 9}

My administrator of special education has requested that his teachers submit their ideas for in-service training. What suggestions would you have in regard to relevant topics and resources?

Accountability is coming to all of education-to the teacher trainer, to the teacher, and to the administrator or consultant in charge of in-service training. No longer can the spiel of an available salesman or an occasional speaker be held up as evidence of a viable in-service training program. Attempts to do so are professional larcenythey rob the instructional staff of their potential for growth.

The following are presented as recommended steps to follow in the development of a viable in-service training program:

Step One: Obtain a commitment from the school board and central administration to support such a program.

Step Two: Secure someone in your district who is willing to serve in charge of the in-service program. This should often be someone other than the administrator who may not be able to commit the time necessary to plan and implement an effective program. (If a member of the instructional staff assumes this major responsibility he should be reimbursed accordingly.)

Step Three: Involve both the administration and the instructional staff in an exploration of potential goals that might be explored in the in-service program. This exploration should culminate with a list of priorities and a designated major goal. Unfortunately, one-shot random presentations or workshops rarely produce the dividends anticipated. Such presentations may excite teachers to initial action. However, without sustained support the teacher generally encounters problems and discards the new approach in favor of her "tried and true" one. The selection of a single major goal will give the in-service program the continuity necessary to support the teacher in this new endeavor.
Step Four: Identify the resources on which to build your in-service program. Commitments must be obtained for: (a) financial support-in addition to the local district consider Title VI and collaboratigh with adjacent districts; (b) time resources-a good program will entail both some release time by the district and some time volunteered by the instructional staff; (c) available expertise-this may be personnel from your district or neighboring districts, publishers with products relevant to your selected goal, staff from an instructional materials center, or personnel from a college or university setting.

Step Five: Develop an in-service program that delineates a year of sequential meetings and activities that are designed to meet your major objective. Your outlined program should list specific objectives, activities, and resources. It should indicate how each staff member will be involved and how the total program will be evaluated.

Possible topics for a major effort of this type might include:

1. Classroom utilization of instructional objectives

2. Classroom assessment for instructional purposes

3. The implementation of resource rooms and/or instructional centers

4. Classroom organization and management through the individual station approach.

5. Behavior management

6. The implementation of a new approach to a subject area (i.e., reading, arithmetic, etc.)

Your professional competence either improves through periodic selected input or deteriorates insidiously from lack of innovative infusions. Make a commitment to yourself and your students through in-service training.

\section{PROBLEM 11}

I have twelve children in my upper primary class. One child isn't reading and this frustrates him. He is both disturbed and disturbing. What are your suggestions?

All readers are invited to send their solution and tell how they would handle Problem 11. The October 1971 issue will summarize contributions by readers. Focus on Exceptional Children will award complimentary subscriptions each month for the best solution. Send your response to the Editorial Offices, Focus on Exception Children, 6635 East Villanova Place, Denver, Colorado 80222. 